\title{
SANIDAD DEL GANADO LECHERO DE LA CUENCA DEL SUR
}

\author{
L uis Olivera Samaniego ${ }^{1}$
}

\section{INTRODUCCIÓN}

La cuenca lechera del sur es la más importante del país debido a su aporte a la producción láctea nacional, por sus proyecciones y por sus posibilidades de desarrollo. Debemos señal ar quemás del $90 \%$ dela producción de la cuenca del sur es producida por Arequipa, siendo la inrigación de Majes (Caylloma) la que produce más del $40 \%$ de ella. Esto es importantemencionarlo, porque la información que se va a proporcionar se sitúaprincipal menteen laimigación deMajes y se plantea como un componente esencial dela situación sani taria de las enfermedades de control oficial, y de otras enfermedades importantes, así como deproblemas deinfertilidad y mastitis.

\section{MARCO GEOGRÁFICO Y POBLACIONAL}

El consumo de leche per cápita en el Perú es de 54 litros, cuando lo recomendado por la FAO es 120 litros/hab/año. Según la OIA (1995), la población de vacunos en el Perú es de 4'512,832; la de vacas lecheras a nivel nacional es de 563,757; y ladeArequipa es 66,200 ( $11.7 \%$ del total nacional ). Laproducción de leche promedio a nivel nacional es de $4.16 \mathrm{~kg}$ en tanto que A requipa y Lima poseen promedios más al tos $(8.07 \mathrm{~kg}), \mathrm{y}$ Cajamarca está cerca del promedio nacional (4.50 kg).

En cinco de las ocho provincias de Arequipa se produce leche. En la provincia de Arequipa, el área de La J oya comprende las irrigaciones LaJ oya Antigua, San Isidro, San Camilo y La Cano. Otra irrigación importante es la de Santa Rita. La provincia de
A requipa tiene dedicado al área forrajera el $67 \%$ de su área cultivada total . Otra provincia importantees Islay, lacual poseetres zonas con un área forrajera que es el 35\% de su área cultivada total. La tercera provincia es Caylloma, la cual tiene dedicadaa su área forrajerael $78 \%$ del total deárea decultivoy aquí se encuentra la irrigación de Majes. La cuarta provincia es Castilla, con sus cuatro sectores y dondee área forrajera es de $32 \%$ del área cultivabletotal. Final mentetenemos la provincia deCondesuyos, consus dos sectores y con el $81 \%$ de área forrajera. En líneas generales, en el departamento de Arequipa, el 58\% del área cultivable es forrajera y cuenta con una producción de le chede477,000 Its/día.

Los porcentajes de producción en la cuenca lechera de Arequipa, en base a sus provincias son: Arequi pa(53.0\%), Caylloma (32.3\%), Islay (6.2\%), Castilla (6.0\%) y Condesuyos (2.5\%). Las másimportantes son A requipa y Caylloma, quienes juntas repre sentan más del $80 \%$ dela producción del de partamento.

Dentro de las posi bilidades que tiene el ganado lechero de Arequi pa, se puede indicar que 300 establos están en control le chero, lo que significa un promedio general deproducción de 14-16 kg delechepor establo, hecho quedifiereen gran proporción con Ios promedios deproducción nacionales. LoS ganaderos que producen de $1-30 \mathrm{~kg}$ diarios, representan el $52.1 \%$ y en volumenel $17.8 \%$. Los que producen de $31-90 \mathrm{~kg}$ representan el $33.6 \%$ y en volumen el $38.0 \%$; y aquel los que producen mas de $90 \mathrm{~kg}$ representan el $13.6 \%$ y en volumen el $44.2 \%$ (Cuadro 3 ).

${ }^{1}$ Médico Veterinario., MSc, Asesor Técnico GLORIA S.A 
Sani dad del ganado lechero delacuenca del Sur

Cuadro 1. Cifras de la cuenca lechera de Arequipa- Año 1997

\begin{tabular}{lcccc}
\hline Zonas Productoras & $\begin{array}{c}\text { Área Total de } \\
\text { Cultivo }(\mathrm{Ha})\end{array}$ & Área Forrajera & № deVacas & $\begin{array}{c}\text { Producción diaria } \\
\text { Comercial (Litros) }\end{array}$ \\
\hline Prov. Arequipa & 28,231 & 18,887 & 23,470 & 253,000 \\
Prov. Islay & 9,194 & 3,199 & 3,910 & 29,500 \\
Prov. Caylloma & 13,689 & 10,726 & 15,600 & 153,500 \\
Prov. Castilla & 14,122 & 4,542 & 4,115 & 29,000 \\
Prov. Condesuyos & 2,040 & 1,660 & 1,875 & 12,000 \\
\hline TOTAL & 67,276 & 39,014 & 48,970 & 477,000 \\
\hline
\end{tabular}

Fuente: Oficina de Información Agraria (OIA) MAG-SENASA-II Censo Nacional Agropecuario

Cuadro 2. Control lechero en las principales zonas de producción del Departamento de Arequipa. Año 2000

\begin{tabular}{lcccc}
\hline Zona & $\begin{array}{c}\text { No de } \\
\text { Establ os }\end{array}$ & Vacas & $\begin{array}{c}\text { Promedio } \\
\text { Producción }\end{array}$ & $\begin{array}{c}\text { Promedio } \\
\text { General }\end{array}$ \\
\hline Santa Rita & 25 & 1,176 & 17.0 & 14.4 \\
San Isidro-La Cano & 58 & 875 & 17.1 & 14.6 \\
Majes & 400 & 4,776 & 16.6 & 13.9 \\
Laj oya Antigua & 23 & 755 & 15.9 & 13.5 \\
\hline
\end{tabular}

Fuente: Control Oficial de Productividad Lechera del Departamento de Arequipa

Cuadro 3. Proveedores de Goria S.A. por rangos de entrega diaria 1992

\begin{tabular}{rcccc}
\hline $\begin{array}{c}\text { Rango } \\
\text { (kg/día) }\end{array}$ & \multicolumn{2}{c}{ Proveedores } & \multicolumn{2}{c}{ Volumen entregado } \\
\hline & № & $\%$ & $\mathrm{~kg} / \mathrm{día}$ & $\%$ \\
\hline $1-30$ & 4,237 & 52.1 & 70,842 & 17,8 \\
$31-90$ & 2,787 & 33.6 & 151,013 & 38,0 \\
$>91$ & 1,106 & 13.6 & 175,459 & 44,2 \\
\hline Total & 8,130 & 100.0 & 397,314 & 100.0 \\
\hline
\end{tabular}

Fuente: Adaptado de Nuestra Leche (1993) 
Enfermedades Bajo Control OFICIAL

Losserviciosdesanidad animal hansido diseñados para prevenir enfermedades infecciosas. En los países del tercer mundo, estos servicios aún están abocados a enfermeda des como Fiebre Aftosa, Brucelosis y Tuberculosis.

\section{Fiebre Aftosa}

En Arequipa no se ha presentado ningún brotedeFiebreAftosa desde 1993, por lo quese está próximo a ser declarada "zona libre sin vacunación". Sin embargo, alcanzar esto ha costado mucho tiempo y dinero, pues cada campaña de vacunación ha representa do paralos ganaderos unainversión deaproximadamente $\$ 100,000$.

Brucelosis

El otro aspecto es el programa decontrol de Brucelosis, el cual ha involucrado ed esfuerzo del sector oficial y de muchos veterinarios durantemuchos años. Desde 1987 se realiza un monitoreo con el apoyo de Labvetsur, con una frecuencia de 3 veces por año practicando la Prueba del Anillo en Leche. Los resultados se muestran en el Cuadro 4.

Vemos que en 1987 hubieron 13 esta blos reactores de un total de 2,864 hatos ana lizados. En estos casos, se visita a cada uno deestos 13 establos problema, setoman muestras de sangre de todos los ani mal es y se realizan las pruebas respectivas, las cuales hasta 1993 eran la prueba de Aglutinación en Placa y la de Rosa de Bengala. Se ha ido ganando en cobertura, llegándose a monitorear a casi la total idad de hatos en Arequi pa.

Según datos de SENASA de 1999, de 6,665 hatos anal izados se encontraron 14 ha tos reactores (0.21\%). Para el año 2000 , de 24,526 hatos eval uados se hallaron 65 hatos reactores $(0.26 \%)$ y dentro de estos se encontró un animal positivo a las pruebas confimatorias deFijación deComplementoy a Rosa de Bengala. A pesar de todo, el porcentaje es bastante bajo y amerita iniciar las acciones para declarar aA requi pa libredeesta enfermedad. Se considera que desde 1987 a la fecha, los ganaderos han pagado cerca de medio millón de dólares para al canzar estos logros.

\section{Tuberculosis}

La Organización Panamericana de la Sal ud (OPS) clasifica a los países de América de acuerdo a sus niveles de esta enfermedad dela siguiente manera:

Categoría A: Número de reactores es me nos de 1/1000

Categoría B: Se tiene un porcentaje considerable de reactores

Categoría C: La situación es desconocida.

El Perú se encuentra en la categoría C, pero no así el sur del país como se aprecia en el Cuadro 6.

En 1994 hubieron 172 ani mal es reactores a la prueba simplecaudal, a quienes seles hizo la prueba doble comparativa, de los cua les resultaron infectados 33 animales, alcanzándose una prevalencia de 0.23 (2/ 1000). En 1995 hubieron 257 animales reactores a la prueba simple caudal, a quienes se les hizo la prueba doble comparativa, de los cual es resul taron infectados 18 ani males, con una preval encia de 0.08 (1/1000).

En 1994, de los 33 animales positivos, solo 8 tuvieron supervisión veterinaria en el beneficio. En 1995, de 18 positivos a la prueba doble comparativa, solo 1 animal tuvo sur pervisión en el beneficio. Lo que ocurre en estas situaciones, es queel ganadero esconde a estos animales, les cambia el arete (identificación) o simplementelos venden.

Se enviaron muestras al INPAAZ (Buenos Aires, Argentina) y en tres de los 8 animales que se sacrificaron en 1994 se pudo aislar el Mycobacterium bovis. 
Cuadro 4. Resultados de la prueba de anillo en leche en hatos lecheros y animales reactores positivos a las PAP y RB del Departamento de Arequipa

\begin{tabular}{ccccc}
\hline \multirow{2}{*}{ Año } & \multicolumn{2}{c}{ Hatos Reactores } & \multicolumn{2}{c}{ Animales infectados } \\
\cline { 2 - 5 } & $\%$ & Positivos/№ hatos & $\%$ & Positivos/№ hatos \\
\hline 1987 & 0.45 & $13 / 2.864$ & 1.00 & $66 / 6,598$ \\
1988 & 1.13 & $59 / 5,222$ & 1.05 & $33 / 3,133$ \\
1989 & 1.39 & $85 / 6,133$ & 3.36 & $65 / 1,936$ \\
1990 & 0.89 & $61 / 6,827$ & 1.06 & $35 / 3,295$ \\
1991 & 1.63 & $106 / 6,498$ & 1.82 & $64 / 3,520$ \\
1992 & 0.94 & $63 / 6,676$ & 0.35 & $8 / 2,273$ \\
1993 & 1.24 & $77 / 6,229$ & 0.18 & $4 / 2,207$ \\
\hline
\end{tabular}

Cuadro 5. Resultados a la Prueba de MRT, Departamento de Arequipa

\begin{tabular}{cccc}
\hline Año & No de Muestras & Hatos Reactores & $\%$ \\
\hline $1999\left(3^{\text {er }}\right.$ monitoreo) & 6,665 & 14 & 0.21 \\
2000 (total $)$ & 24,526 & $65^{*}$ & 0.26 \\
\hline
\end{tabular}

* 1 animal positivo, confirmado a la PRB y FC. Fuente: SENASA (2001)

Cuadro 6. Resultados de la tuberculinización prueba simple caudal, irrigación de Majes (1988-1995)

\begin{tabular}{cccc}
\hline Año & Animales Inoculados & Reactores & $\begin{array}{c}\text { Prevalencia } \\
\%\end{array}$ \\
\hline 1988 & 11,955 & 35 & 0.29 \\
1989 & 7,818 & 04 & 0.05 \\
1991 & 14,695 & 23 & 0.15 \\
1992 & 15,366 & 47 & 0.30 \\
1993 & 15,000 & 37 & 0.24 \\
1994 & 13,763 & 172 & 1.24 \\
1995 & 21,238 & 257 & 1.21 \\
1996 & 20,050 & 135 & 0.67 \\
\hline
\end{tabular}

Fuente: Convenio ALA/02

Cuadro 7. Resultados de la Tubercul inización: Prueba Doble Comparativa. Irrigación Majes

\begin{tabular}{cccc}
\hline Año & Animales Reactores & Animales & Prevalencia \\
\hline 1994 & 172 & 33 & 0,23 \\
1995 & 257 & 18 & 0,08 \\
\hline
\end{tabular}

Fuente: Convenio ALA/02 
Estas campañas oficiales representan el esfuerzo de muchos médicos veterinarios. Enel año 2000 intervinieron 54 profesionales para inocul ar a 80,000 animales, quienes vienen a ser el $95.7 \%$ del total y dondesehallóa través dela prueba simple caudal a 79 anima les positivos (menos de 1/1000).

De los 79 animales reactores, 66 dieron positivo a la prueba doble comparativay el resto no pudo ser ubicado. Sin embargo, del total depositivos, sólo 4 tuvieron supervisión de matanza, por lo tanto son muchos los animales positivos, que se libran del sacrificio convirtiéndose en focos infecciosos con ca pacidad de contagiar a sus compañeros de hato eimpidiendo la erradi cación dela enfermedad. La eliminación de animal es positivos no es simple pues para un ganadero que poseel0 vacas, eliminaraunalesignificae $10 \%$, es decir una gran pérdi da queno está dispuesto a asumir.

Otra dificultad que se observa dentro de este proceso, es que cuando se captura a estos animales, muchas veces no presentan lesiones evidentes, hecho queresul tafrecuente cuando la preval encia es baja. Cuando la preval encia presenta esta característica, los animalessin lesiones visibles aumentan hasta en un $5 \%$.

Falta una acción más decidida de los ganaderos y técni cos para eliminar a estos animales y además para que haya una vigilancia estrechacon pruebas detuberculinización, con pruebas demayor sensibili dad y especificidad que la prueba de tuberculina. Actual mente existen otras pruebas quejunto alatuberculina pueden dar una exactitud del diagnóstico. Actualmente para el diagnóstico del Mycobacterium spp existen nuevos medios decrecimiento, dondelacondición depositivo se detecta hasta en 7-10 días, mientras que con los medios tradicionales las colonias de bacterias crecen en mes y medio. Así también, mediante pruebas como e PCR sepue den obtener resul tados hasta en 2 días. Estas son tecnologías necesarias para zonas de alta producción deleche.

\section{Otras Enfermedades}

\section{Fasciolasis}

Se ha definido en 3 grupos de acuerdo a la presencia de huevos en las heces. Según la prevalencia tenemos de 1-10\% (bajo), de $11-49 \%$ (mediano) y más de 50\% (alto). El seguimiento de esta enfermedad se ha hecho mediantelainspección dehígados debovinos en los camal es dela I rrigación de Majes dondeseha encontrado quee $34 \%$ delos animales presentan lesiones hepáticas.

Enfermedades causadas por Protozoarios y Ricketsias

En el ganado dela Irrigación de Majes se encontró $7.6 \%$ de animales positivos a Babesia bigemina y $28 \%$ de animales positivos a Anaplasma marginale (Alvarez, 1996).

\section{L eucosis Bovina}

La Leucosis Bovina es otra enferme dad importante en producción lechera. Esta hasido muy estudiada por la Dra Hermelinda Rivera de la FMV-UNMSM, quien en un estudio en animales de la cuenca halló una seroprevalencia de $12.8 \%$. En ese mismo estudio se halló a nivel de hatos $14.6 \%$. Estos porcentajes son bajos y justifican los esfuerzos para erradicar la enfermedad en el valle.

\section{ABORTOS}

Diarrea Viral Bovina (BVD)

Los abortos vienen a constituir un problemacrecienteen al gunas zonas deA requipa. Gloria S.A. hizo una encuesta en una irrigación y encontró una preval encia promedio de $16 \%$, con rangos entre $3-30 \%$.

IBR (Rinotraqueitis Infecciosa Bovina)

Se ha encontrado una prevalencia de $20 \%$. Se le considera un agentemenor dentro de las causas de aborto. 
Cuadro 8. Fasciolasis en las principales áreas de producción lechera del Departamento de Arequipa

\begin{tabular}{clcl}
\hline Riesgo & \multicolumn{1}{c}{ Zona } & Prevalencia & \multicolumn{1}{c}{ Autor } \\
\hline \multirow{2}{*}{ Alto } & I. Majes - B & 55.6 & Meza, D (2000) \\
& I. Majes- D & 51.9 & Meza, D (2000) \\
& S. Rita & 19.4 & Calisaya (1998) \\
& I. La oya & 10.5 & Manrique, J (1999) \\
Mediano & I. Majes- C & 44.2 & Meza, D (1999) \\
& I. La Cano & 14.5 & Chávez, J (1999) \\
& I. San Isidro & 10.9 & Chávez, J (1999) \\
& Pampacolca & 5.6 & \\
\multirow{3}{*}{ Bajo } & I. Majes - A & 7.8 & Meza, D (2000) \\
& I. Majes- B & 9.6 & Meza, D (2000) \\
\hline
\end{tabular}

Fuente: Labvetsur (2000)

$34 \%$ positivos (Camal de La Colina. I. Majes)

Cuadro 9. Seropreval encia del virus de Leucosis Bovina en animal es de la cuenca lechera de Arequipa

\begin{tabular}{lccc}
\hline Sector & $\begin{array}{c}\text { Muestras } \\
(\mathrm{n})\end{array}$ & $\begin{array}{c}\text { Positivos } \\
(\mathrm{n})\end{array}$ & $\begin{array}{c}\text { Prevalencia } \\
\%\end{array}$ \\
\hline S. Rita & 82 & 17 & $20.7 \pm 8.8$ \\
El Cural & 29 & 4 & $13.8 \pm 12.6$ \\
LaJ oya & 29 & 3 & $10.3 \pm 11.1$ \\
Vitor & 28 & 4 & $14.3 \pm 13.0$ \\
Islay & 42 & 4 & $9.5 \pm 9.0$ \\
Zamácola & 61 & 12 & $19.7 \pm 10.0$ \\
Majes & 113 & 8 & $7.1 \pm 4.3$ \\
Chiguata & 26 & 0 & 0 \\
\hline Total & 410 & 52 & $12.8 \pm 3.2$ \\
\hline
\end{tabular}

Fuente: Flores y Rivera (2000)

Cuadro 10. Seropreval encia a BVD en gnado lechero de Arequipa

\begin{tabular}{ccl}
\hline Año & Prevalencia (\%) & Autor \\
\hline $1991-1997$ & 89.0 & Rivera, H. \\
1997 & 21.9 & Paredes, D. \\
1999 & 65.0 & Manrique, J. \\
1997 & 78.5 & Barriga, E \\
\hline
\end{tabular}

Fuente: Labvetsur (2000) 
Cuadro 11. Preval encia deIBR en el departamento de Arequipa

\begin{tabular}{ccl}
\hline Año & Prevalencia (\%) & \multicolumn{1}{c}{ Autor } \\
\hline $1991-1997$ & 22.0 & Rivera, H \\
2000 & 10.2 & Paredes, D \\
1997 & 24.0 & Labvetsur (Informe anual) \\
1998 & 24.5 & Labvetsur (Informe Anual) \\
1997 & 18.6 & Barriga, E \\
\hline
\end{tabular}

Fuente: Labvetsur (2000)

Virus neutralización en madres, e IF en placenta y feto

N eospor osis

Seleconsidera un importantecausante de abortos en la cuenca del sur (Neospora caninum). Se ha realizado la prueba de inmunoflorescenciaindirecta encontrándose un $60 \%$ de prevalencia.

\section{L eptospirosis}

Se han real izado pruebas de agl utinacióny deesta evaluación sehaaisl ado diversos serovares. El Hardjo es el demayor preocupación.

Frente a la problemática de abortos, debernos mencionar que si se implementan las acciones para declarar a Arequipa zona libredebrucel osis, las medidas podrían también desplegarse hacia las otras patologías. Laregulación dela OIE obligaa los ganaderos y veterinarios a entregar las placentas y fetosalos laboratorios dediagnóstico, dema nera que estos puedan hacer una investiga ción de todos estos agentes causales para crear unaestadística delosmismos, propuesta alaquenos aunamos parael control deabortos en el ganado de la cuenca del sur.

\section{Eficiencia Reproductiva}

Estainformación derivadeunaencuesta que se realizó en la Irrigación de Majes para cuantificar el Intervalo entre Partos (IEP) y el Interval o Parto Concepción (IPC).
Se encontró que el IEP era 15 meses por lo que se diseñó un programa preventivo para disminuir los días abiertos. Básicamente, este esquema tenía como meta reducir el IEP a 13 meses, de manera que los animales que tuvieran más de 110 días eran sobre quienes se tenía que trabajar.

La metodología era visitar una vez al mes a los ganaderos para realizar una eva luación de sus vacas en diferentes momentos:

a) Involución uterinaalos 25 días postparto.

b) Función ovárica a los 45 días postparto.

c) Diagnóstico de preñez sobre los 40 días postinseminación.

d) Examinar y dar tratamiento a los animales problema, conocidos como animales repetidores (más de tres servicios).

Seinscribieron 200 parcelas con 13 va cas como promedio de hato. En los tres primeros controles se comenzó con 201 días abiertos en tanto queen los úl timos controles bajó a 156 días. Como era un programa nue vo se cobró 60 centavos de dól ar dando como resul tado un costo beneficio de 1:22 quecreó gran entusiasmo entre los ganaderos.

Lo que seencontró en los ani males de días abiertos ampli ios fue que ninguno supe raba los dos servicios por preñez. En el exa men de ovarios a 107 vacas se encontró estados de aciclia (ovarios lisos y ovarios 
Cuadro 12. Seropreval encia* a Neospora caninumen ganado lechero del departamento de Arequipa

\begin{tabular}{cccc}
\hline Año & Muestras & Prevalencia \% & Autor \\
\hline 1997 & & 57.0 & SENASA-Arequipa \\
1999 & 18 & 55.6 & Labvetsur \\
2000 & 10 & 70.0 & Olivera, L \\
2000 & 12 & 40.0 & Olivera, L \\
\hline
\end{tabular}

* Prueba: inmunofluorescencia indirecta

Cuadro 13. Prevalencia a Leptospi rosis en el departamento de Arequipa

\begin{tabular}{cccl}
\hline Año & Muestras & Prevalencia (\%) & \multicolumn{1}{c}{ Serovares de L. interrogans } \\
\hline 1998 & & 30.4 & $\begin{array}{l}\text { L. pomona, L. hardjo, L. icterohaemorragica, L. } \\
\text { bratislava, L. ballum }\end{array}$ \\
1997 & 65 & 55.3 & L. canícola, L. icterohaemorragica, L. hardjo \\
1998 & 55 & 25.5 & L. giorgia, L. canicola, L. pomona, L. ballum \\
1999 & 10.9 & L. bratislava, L. pomona \\
\hline
\end{tabular}

Fuente: Labvetsur (2000)

Prueba:MAT +> 1:1000 - 1:1400

atróficos) en la mitad deellos. Estos resulta dossevolvieron a repetir en un segundo control dos semanas mas tarde, por lo que fueron sacrificados estos animales. Estos problemas son debidos básicamente a manejo.

Otro examen complementario se rea lizó a vacas repetidoras, quienes tenían tratamientos bastante diversos en los que se incluía el uso de hormonas encontrándose el $16 \%$ de ellas con metritis.

M astitis

Con un trabajo promovido por Gloria S.A. se eval uaron 74 establos haciéndose el conteo de cálulas somáticas y se pudo ver quesolo 5 establos (9\%), presentó menos de 600,000 célul as somáticas.

\section{Conclusiones}

Las buenas noticias para Arequipason que se encuentra libre de Fiebre Aftosa y está próximo a ser libre de Brucelosis y de Tuberculosis. Asimismo, es posiblecontrolar y erradicar la leucosis y las princi pales causas deaborto en un periodo detiempo no muy prolongado. Por otro lado, esta zona continúa sufriendo grandes pérdidas económicas debido a causal es de infertilidad y mastitis. 
Cuadro 14. Programa preventivo reproductivo en la Irrigación Majes. Resul tados preliminares de 9 meses sobreed interval o parto-concepción

\begin{tabular}{|c|c|c|c|c|c|c|c|c|c|c|c|}
\hline \multirow[b]{2}{*}{ Resultado } & \multicolumn{10}{|c|}{ Establo } & \multirow[b]{2}{*}{ Promedio } \\
\hline & $A$ & B & $C$ & D & E & $F$ & $\mathrm{G}$ & $\mathrm{H}$ & I & $J$ & \\
\hline Inicial & 176 & 226 & 219 & 242 & 219 & 173 & 243 & 163 & 110 & 238 & 201 \\
\hline Final & 88 & 154 & 171 & 261 & 197 & 118 & 172 & 117 & 116 & 163 & 156 \\
\hline Dif. & 88 & 72 & 38 & -19 & 22 & 55 & 71 & 46 & -6 & 65 & 45 \\
\hline № Vacas & 13 & 14 & 13 & 10 & 13 & 9 & 17 & 19 & 11 & 15 & 13 \\
\hline \multicolumn{9}{|c|}{ Costo $\times 9$ visitas, establo promedio: 13 × S/1.25 x 9} & \multicolumn{3}{|c|}{ S/. 146.00} \\
\hline \multicolumn{9}{|c|}{ Beneficio por disminución de días vacíos 13 × 45 × \$2.18 × 2.61} & \multicolumn{3}{|c|}{$3,328.00$} \\
\hline \multicolumn{9}{|c|}{ Costo-beneficio del Programa } & \multicolumn{3}{|c|}{$1: 22$} \\
\hline
\end{tabular}

Fuente: Convenio ALA/02

Cuadro 15. Prevalencia de mastitis subclínica en establ os de LaJ oya

№ de Establos

Recuento de Células

\begin{tabular}{rc}
\hline 5 & $<600$ \\
34 & 600 a 1,000 \\
35 & $>1,000$ \\
\hline
\end{tabular}

Fuente: Orihuela (1995) 